\title{
Chitosan/Octadecylamine-Montmorillonite Nanocomposite Containing Nigella arvensis Extract as Improved Antimicrobial Biofilm Against Foodborne Pathogens
}

\author{
Sedef ilk ${ }^{1} \cdot$ Mehmet Şener $^{2} \cdot$ Mehtap Vural $^{3} \cdot$ Sedat Serçe $^{3}$ \\ Published online: 12 October 2018 \\ (C) Springer Science+Business Media, LLC, part of Springer Nature 2018
}

\begin{abstract}
The objective of this study was to develop inexpensive and facile nanocomposites based on chitosan and organo-clay with the antimicrobial affectivity that provide the serious challenges caused by bacterial infections in various products such as food packaging materials. The chitosan with octadecylamine montmorillonite (ODA-MMT) nanocomposites by supplementing 1, 2.5 , and $5 \mathrm{w} \%$ Nigella arvensis seed (black cumin) extract (CMBC-1, CMBC-2.5, and CMBC-5) were prepared chitosan from ionic liquid solutions in the presence of ODA-MMT and black cumin extract suspension. The effect of black cumin with different content on the structure and antimicrobial activity of the nanocomposite have been investigated. The interactions between the chitosan matrix, ODA-MMT, and black cumin extract at different conditions were characterized both physicochemically (FT-IR, $\mathrm{SEM}$, and XRD) and biologically (antimicrobial). The results indicated that the formation of exfoliated nanostructure of nanocomposites was provided by loading of nanodispersed clay in matrix. Antimicrobial activity of CMBC nanocomposite film was evaluated using disc diffusion method against Gram-negative bacteria Escherichia coli ATCC 25922 and Salmonella enterica serotype Typhimurium SL 1344 and Gram-positives Staphylococcus aureus ATCC 25923 and Streptococcus mutans ATCC 25175. The antimicrobial activity studies of the CMBCs illustrated that the nanocomposites could more strongly inhibit the growth of the tested Gram-negative bacteria than Gram-positive bacteria within increased content of black cumin from 1 to $5 \mathrm{w} \%$. To our knowledge, this is the first report on the antimicrobial effect of CMBC nanocomposite film. Such biomaterials within nontoxic and inexpensive properties will thus have great potential applications in the development of new packing materials that can effectively prevent the antimicrobial formation.
\end{abstract}

Keywords Chitosan $\cdot$ ODA-MMT $\cdot$ Nigella arvensis $\cdot$ Polymer-layered silicate nanocomposite $\cdot$ Active food package Antimicrobial supplement

\section{Highlights}

- The biopolymeric chitosan/ODA-MMT nanocomposite film containing black cumin extract with different concentrations (CMBC) was prepared. - For the first time, significant inhibition against the common food pathogen microorganisms was observed using the novel CMBC film.

- $\mathrm{CMBC}$ may have the potential in the development of new antimicrobial package film or additives.

Sedef İlk

sedefilk@ohu.edu.tr; sedefilk3@gmail.com

1 Central Laboratory Research Center, Niğde Ömer Halisdemir University, 51240 Niğde, Turkey

2 Department of Geology, Faculty of Engineering, Niğde Ömer Halisdemir University, 51240 Niğde, Turkey

3 Department of Agricultural Genetic Engineering, Faculty of Agricultural Sciences and Technologies, Niğde Ömer Halisdemir University, 51240 Niğde, Turkey

\section{Introduction}

Bio-based food packaging materials have gained enormous interest among the customers due to high number of advantages such as nontoxicity, eco-friendly (biodegradable), acceptable level of physicochemical properties, and antimicrobial nature [1]. Combination of biopolymers with nanofillers with the reactive and increased surface areas/volume ratio has been provided as an attractive way to develop active and stable food packaging materials of organic-inorganic nanohybrid with properties that are inherent to both types of components. Polymer/clay nanocomposites have gained significant attention in recent years due to the excellent enhancement in chemical and physical properties $[2,3]$. The traditional nonbiodegradable polymers have considerably toxic for the ecosystem. Biopolymers, which are the most abundant class of natural 
biomacromolecules, have attracted increasing attention in the last decade, due to their biocompatibility, low cost, nontoxicity to environment, and various superior physical properties [4]. Chitosan, de-acetylated form of chitin, is the second largest biopolymer followed by cellulose [5]. Chitosan is composed mainly of repeating units of D-glucosamine and $\mathrm{N}$-acetyl-D-glucosamine linked through $\beta-(1-4)$ bond [6]. The antimicrobial properties of chitosan are attributed to its cationic nature which interacts with the negatively charged microbial cell surface, consequently resulting in membrane damage [7]. Chitosan has good biodegradability, biocompatibility, and mechanical properties; however, its thermal gas barrier, stability, and hardness properties are not good enough for it to be used in some applications. Thus, chitosan with nanofiller composite technology provides the enhancement of properties of chitosan $[8,9]$. Organo-clays are surface-modified fillers with organic surfactants by in situ intercalation process. ODA-MMT is also one of commercial organo-clay derivate and widely used in producing nanocomposite [10].

The biopolymer/clay nanocomposite films can be used as a carrier of natural active substances (antioxidant and antimicrobial) which could contribute to the enhancement of shelf life and also offer a more control release of any food ingredient [11]. Up to date, many studies have been focused on production of active food package nanocomposite film enriched with certain natural antioxidant and antimicrobial agents [12-15]. However, still many plants and their fruit-based extracts need to be characterized for their antimicrobial properties in production of food packaging films.

Medicinal plants known as therapeutic plants have been thought to be safe as to modern medical cares. Nigella genus is from Ranunculaceae family, and there has been 13 species described from Turkish flora $[16,17]$. Among these species, $N$. sativa, $N$. arvensis, $N$. damascene, $N$. hispanica, $N$. nigellastrum, and $N$. orientalis were characterized by antimicrobial and anti-inflammatory properties against pathogenic microorganisms [18]. Of the Nigella species that have been investigated biologically for many times, the economically viable $N$. arvensis plant is widely produced in many countries [19]. Seeds of genus $N$. arvensis (black cumin) from Ranunculaceae family have been used medically in the Eastern Europe, Middle East, and Western Asia countries due to therapeutic effect for many diseases such as diuretic, gastroprotective, immune-modulatory, antidiabetic, antihypertensive, anticancer, antimicrobial, anti-inflammatory, and antioxidant properties while bioactive compounds have been derived in distinctive extract of seeds [20-22]. These compounds have important functionality for applications in chemical, pharmaceutical, and food industries. However, these compounds have very poor bioavailability to an oxidizing environment, as light, moisture, temperature, oxygen, etc. owing to the presence of unsaturated bonds in their molecules [23, 24]. Hence, encapsulation or immobilization in polymer matrix enhances their benefits and stability.

In the current study, for the first time, chitosan/ODAMMT-based nanocomposite film enriched with seed extract of $N$. arvensis (black cumin) were produced. Herein, we report on the preparation of green nanocomposites of chitosan/ODAMMT/black cumin, characterization of their hydrogen bonding, amorphous transformation and surface morphology, and evaluation of bactericidal potential against human and food pathogen bacteria. To our knowledge, this is the first reported chitosan/ODA-MMT/black cumin nanocomposite that exhibits significant antibacterial effect.

\section{Materials and Methods}

\subsection{Materials}

Medium molecular weight chitosan (CS) with deacetylation degree of $\sim 80 \%$, ODA-MMT, and glacial acetic acid were supplied by Sigma-Aldrich. For microbial assay, LuriaBertani (LB) was purchased from LABM. Other chemicals were analytical grade reagent. Black cumin $(\mathrm{BC})$ seeds were harvested from Niğde Turkey and stored at $4{ }^{\circ} \mathrm{C}$ until analyzed. Samples were firstly ground manually. Then, seeds at different concentrations $(1,2.5$, and $5 \%, w / v)$ were homogenized in distilled water at $50{ }^{\circ} \mathrm{C}$ by using reactor.

\subsection{Preparation of Nanocomposite Film}

CS $(2 \%, w / v)$ was dissolved in acetic acid solution $(1 \%, v / v)$ at $60^{\circ} \mathrm{C}$ and stirred for $30 \mathrm{~min}$ to obtain a homogeneous mixture. ODA-MMT $\left(5 \%, w_{\text {chitosan }} / v\right)$ was added into the CS gel, and the mixture was stirred at $60{ }^{\circ} \mathrm{C}$. The prepared each BC solution at different concentration $(1,2.5$, and $5 \%, w / v)$ was added into the CS/ODA-MMT (CM) gel solutions. The CS/ODA$\mathrm{MMT} / \mathrm{BC}$ solution was poured into petri dishes and allowed to dry at room temperature for $12 \mathrm{~h}$. CM nanocomposites prepared in this study with different black cumin content (1, $2.5,5 \%, w / v)$ will be referred as CMBC-1, CMBC-2.5, and CMBC-5, respectively.

\subsection{Characterization of Chemical Composition}

The hydrogen bonding of pristine $\mathrm{BC}$ extract, CS, ODAMMT, and obtained nanocomposites: CM, CMBC-1, CMBC-2.5, and CMBC-5 were evaluated by using Fourier transform infrared spectroscopy (FTIR, Perkin Elmer Nicolet 520 spectrophotometer, Boston, USA). The samples were analyzed using 16 scans in the range of $450-4000 \mathrm{~cm}^{-1}$ with $4 \mathrm{~cm}^{-1}$ resolutions for the FTIR analysis. 


\subsection{Morphology Observations}

Scanning electron microscopy (SEM) (Zeiss, Evo 40) was used for the evaluation of the surface morphology of the synthesized CM, CMBC-1, CMBC-2.5, and CMBC-5. Nanoparticles were mounted onto aluminum pin-type stubs (diameter $12 \mathrm{~mm}$ ) with carbon tape, and then, nanoparticles were coated with palladium-gold for the SEM measurements.

\subsection{Amorphous Transformation Properties}

$\mathrm{X}$-ray diffractometer (XRD) were used to determine change in the crystal polymorphism of CS, ODA-MMT, and nanocomposites: CM, CMBC-1, CMBC-2.5, and CMBC-5. The crystalline structures of samples were obtained using the XRD (Panalytical, Empyrean) with $\mathrm{Cu}-\mathrm{K} \alpha$ radiation. Measurements were carried out at $45 \mathrm{kV}$ and $40 \mathrm{~mA}$ condition. The scanned angle was set from $2^{\circ} \leq 2 \theta \leq 40^{\circ}$, and the scan rate was $1^{\circ} \mathrm{min}^{-1}$. All samples were analyzed and recorded in triplicate.

\subsection{Antimicrobial Bioassay}

The following microorganisms including Escherichia coli (E. coli) ATCC 25922, Staphylococcus aureus (S. aureus) ATCC 25923, Streptococcus mutans (S. mutans) ATCC 25175, and Salmonella enterica serotype Typhimurium (S. typhimurium) SL 1344 were used as the tested microorganisms. Stock cultures were prepared and stored with $30 \%$ glycerol at $-80{ }^{\circ} \mathrm{C}$. When cultured from stock, the strains were subcultured before use. All microorganisms were subcultured on LB agar culture at $37^{\circ} \mathrm{C}$ for $24 \mathrm{~h}$.

Antimicrobial activities of BC, CS, ODA-MMT, the synthesized CM, CMBC-1, CMBC-2.5, and CMBC-5 against the tested human pathogen microorganisms were determined by using disc diffusion method [25]. For the assay, firstly, the stock solutions of CS, ODA-MMT, and BC and their composite $\mathrm{CM}, \mathrm{CMBC}-1, \mathrm{CMBC}-2.5$, and $\mathrm{CMBC}-5$ which were used directly after the obtained form of the synthesis process. The microorganisms' turbidity was set by $0.5 \mathrm{McF}$ arland standard as a reference. The prepared samples were stand under UV irradiation for sterilization. The suspension of microorganism $(100 \mu \mathrm{L})$ was inoculated $\left(10^{6}\right.$ cells $\left./ \mathrm{mL}\right)$ onto petri plate within Müller-Hinton agar, and then, filter discs (diameter $6 \mathrm{~mm}$ ) containing samples $(20 \mu \mathrm{L})$ were placed on the prepared petri plate and incubated at $37^{\circ} \mathrm{C}$ for $24 \mathrm{~h}$. Gentamicin $(20 \mu \mathrm{g} / \mathrm{disc})$ was used as positive control, and the disc containing only solvent (acetic acid 1\%,v/v) was used as a negative control. All tests were repeated in three times. The diameter of inhibition zone was calculated after incubation. The results were presented as mean diameter of inhibition zone in $\mathrm{mm} \pm$ standard deviation (mean $\pm \mathrm{SD}$ ).

\section{Results and Discussion}

The polycationic and hydrophilic properties of CS in acidic media provided a good intercalated and exfoliated nanocomposite form owing to molecules of CS biopolymer were easily located and well dispersed into the interlayers of the ODAMMT silicates by cationic exchange mechanism [26]. It can be presumed that the interaction between biopolymer CS and exfoliated ODA-MMT sheets ensures the formation of bonding in between, which further generates a strong cross-linking structure in the final nanocomposite structure (Fig. 1).

\subsection{Structural Analyses of CMBC Nanocomposites}

The structural analyses based on FTIR, XRD, and SEM methods were carried out to investigate the morphology, and the interactions between nanofillers and chitosan matrix also within biomolecules of black cumin extract.

First, FTIR analysis was performed to confirm the presence of chitosan, ODA-MMT nanofillers, and black cumin extract in the nanocomposites, and study the interactions between the cellulose matrix, ODA-MMT, and black cumin (Fig. 2). The absorption peak observed at $3518 \mathrm{~cm}^{-1}$ in the FTIR spectrum of pristine ODA-MMT (Fig. 2b) was illustrated to stretching vibration of Al-Al-OH groups in the octahedral layer. The peaks observed at $1504 \mathrm{~cm}^{-1}$ and $1478 \mathrm{~cm}^{-1}$ were out of plane wagging of $\mathrm{OH}$ group. The sharp peak at $1012 \mathrm{~cm}^{-1}$ was attributed to Si-O stretching vibration. Tetrahedral bending modes were observed at $509 \mathrm{~cm}^{-1}$ for $\mathrm{Si}-\mathrm{O}-\mathrm{Al}$ and at $487 \mathrm{~cm}^{-1}$ for Si-O-Mg [27]. The important differences were observed at $\mathrm{O}-\mathrm{H}$ stretching vibrations when FTIR spectra of $\mathrm{CM}$ films and pure CS and ODA-MMT were compared. The absorption peak shifting illustrated strong interactions between CS matrix and ODA-MMT clay which formed by hydrogen bonding (Fig. 2b-d). It was also observed at the C-O stretching vibration region in the range of $952-1073 \mathrm{~cm}^{-1}$ as a wide band for pure CS film, but this range was expanded to 905-1123 $\mathrm{cm}^{-1}$ interval for the CM film (Fig. 2d). The absorption bands of $\mathrm{CM}$ film were related to $\mathrm{O}-\mathrm{H}$ stretching at $3478 \mathrm{~cm}^{-1}$, C-H stretching at $2804 \mathrm{~cm}^{-1}$, C-O carbonyl stretching from the chitosan at $1586 \mathrm{~cm}^{-1}, \mathrm{C}-\mathrm{O}$ stretching at $989-1128 \mathrm{~cm}^{-1}$, and $\mathrm{O}-\mathrm{CH} 3$ stretching at $857 \mathrm{~cm}^{-1}$ from asymmetric oxygen bridge. Small absorption bands in the range of 1254-1448 $\mathrm{cm}^{-1}$ illustrated the characteristics band of C-H for CM (Fig. 2d) and C-H vibrations observed as small bands in the range of 486-604 $\mathrm{cm}^{-1}$ [28]. We suggested that the hydroxylated edge-edge interaction of the silicate layers provided the intercalated and exfoliated structure of CM nanocomposite [10]. While hydroxyl functional groups of each CS unit can form hydrogen bonds with hydroxylated edge groups of the silicate layers, and thus, it leads to the strong interaction between CS matrix and ODA-MMT layers. New absorption bands were obtained in the FTIR spectra of CMBC film with 
Fig. 1 Schematic illustration of $\mathrm{CMBC}$ biofilm preparation

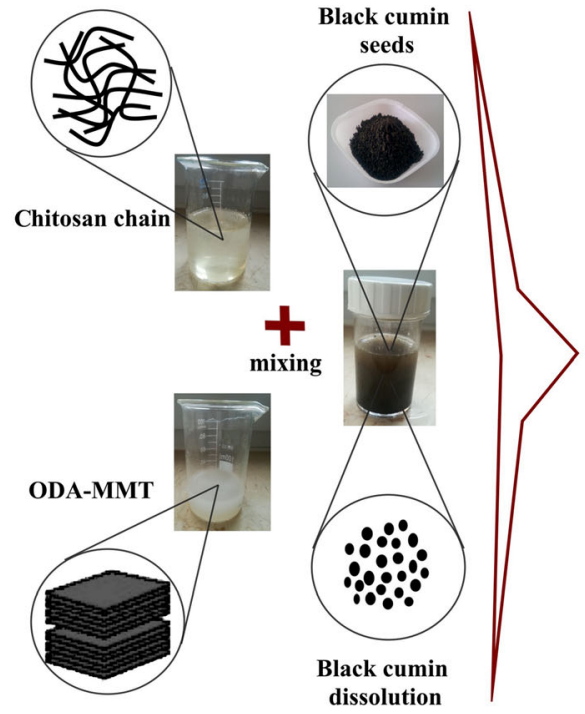

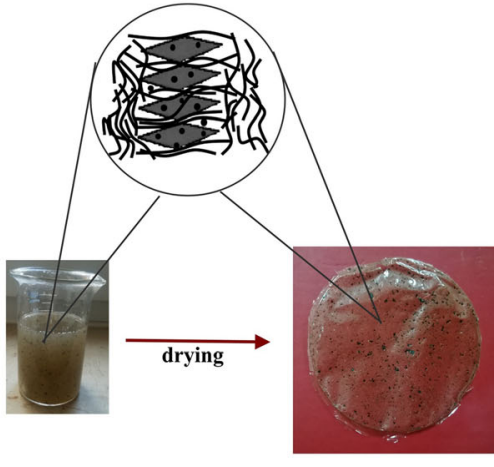

Chitosan/ODA-MMT/Black Cumin Nanocomposite Film the addition of $\mathrm{BC}$ into the $\mathrm{CM}$ film matrix (Fig. 2e-g). For pure CM film, O-H stretching vibration seen at $3478 \mathrm{~cm}^{-1}$ was disappeared because of $\mathrm{O}-\mathrm{H}$ stretching vibration of phenolic group of black cumin (Fig. 2a). O-H intensity of stretching vibration obtained at $3237 \mathrm{~cm}^{-1}$ and $3489 \mathrm{~cm}^{-1}$ for CM films was decreased and shifted for the CMBC film. The hydrogen bond interaction of phenolic group of black cumin with $\mathrm{CM}$ film may lead to the decreased formation of this band vibration (Fig. 2e-g). C-H stretching vibration obtained at $2802 \mathrm{~cm}^{-1}$ for CM films was shifted to $2785 \mathrm{~cm}^{-1}$ for CMBC film. Also, the intensity of $\mathrm{C}-\mathrm{H}$ stretching was increased with increased amount of black cumin from CMBC1 to CMBC-5 (Fig. 2e-g). The obtained shifts in the absorption bands of CMBC present the interactions between black cumin and $\mathrm{CM}$ film.

Furthermore, the interaction between ODA-MMT, chitosan matrix and black cumin extract has been evaluated by XRD analyses (Fig. 3). The XRD pattern of the ODA-MMT shows a reflection peak at about $2 \theta=7.5,19.5,24,26$, and 35.5 (Fig. 3a). The XRD pattern of CS shows the characteristic crystalline peaks at around $2 \theta=11$ and 22.5 (Fig. 3b). After incorporating CS in ODA-MMT plates, the basal plane of MMT at $2 \theta=7.5$ disappears, substituted by a new weakened broad peak at around $2 \theta=9.5$. Also, the sharp peak at about $2 \theta=$ 19.5 of ODA-MMT almost disappeared and a new characteristic peak at about $2 \theta=26$ was obtained for CM film (Fig. 3c). The peak broadening and intensity decrease, and the shifting of the lower angle to higher reflection most likely illustrates the intercalated or exfoliated structure of nanocomposites [3, 26]. Comparing CMBC films with CM film (Fig. 3c), it is clearly shown that $\mathrm{CM}$ without black cumin residue displays higher crystalline than that of CMBC films (Fig. 3d). For the $\mathrm{CM}$ film containing different content of black cumin residue, the all of CMBC films exhibits two weak crystalline peaks at $2 \theta=9.5$ and $2 \theta=11.5$ with a strong broad slope around $2 \theta=$ 26 , indicating the formation of an amorphous structure (Fig. $3 \mathrm{~d}-\mathrm{f}$ ). With increasing the content of the black cumin from 1 to $5 \mathrm{mg} \mathrm{mL}^{-1}$, the $\mathrm{CMBC}$ film clearly shows intercalated
Fig. 2 FTIR spectra of the black cumin extract (a), ODA-MMT (b), pure chitosan (c), chitosan/ ODA-MMT nanocomposites (d), and $\mathrm{CM}$ nanocomposite entrapment with different black cumin content $(1,2.5,5 \%, w / v)$ referred as CMBC-1 (e), CMBC-2.5 (f), and CMBC-5 (g), respectively

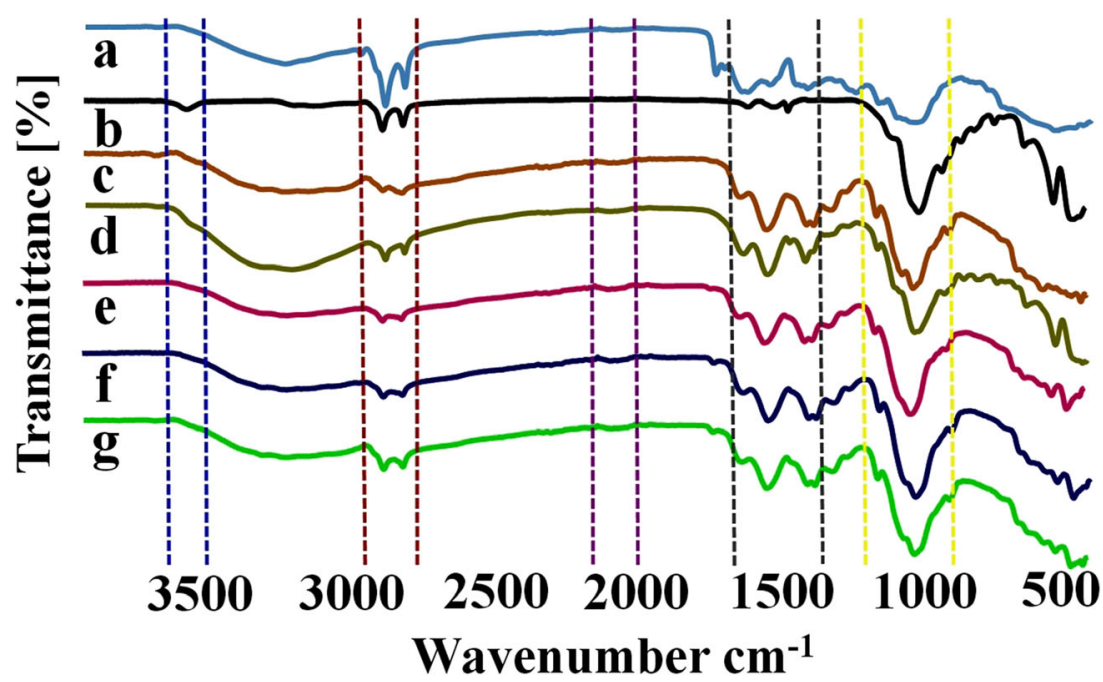




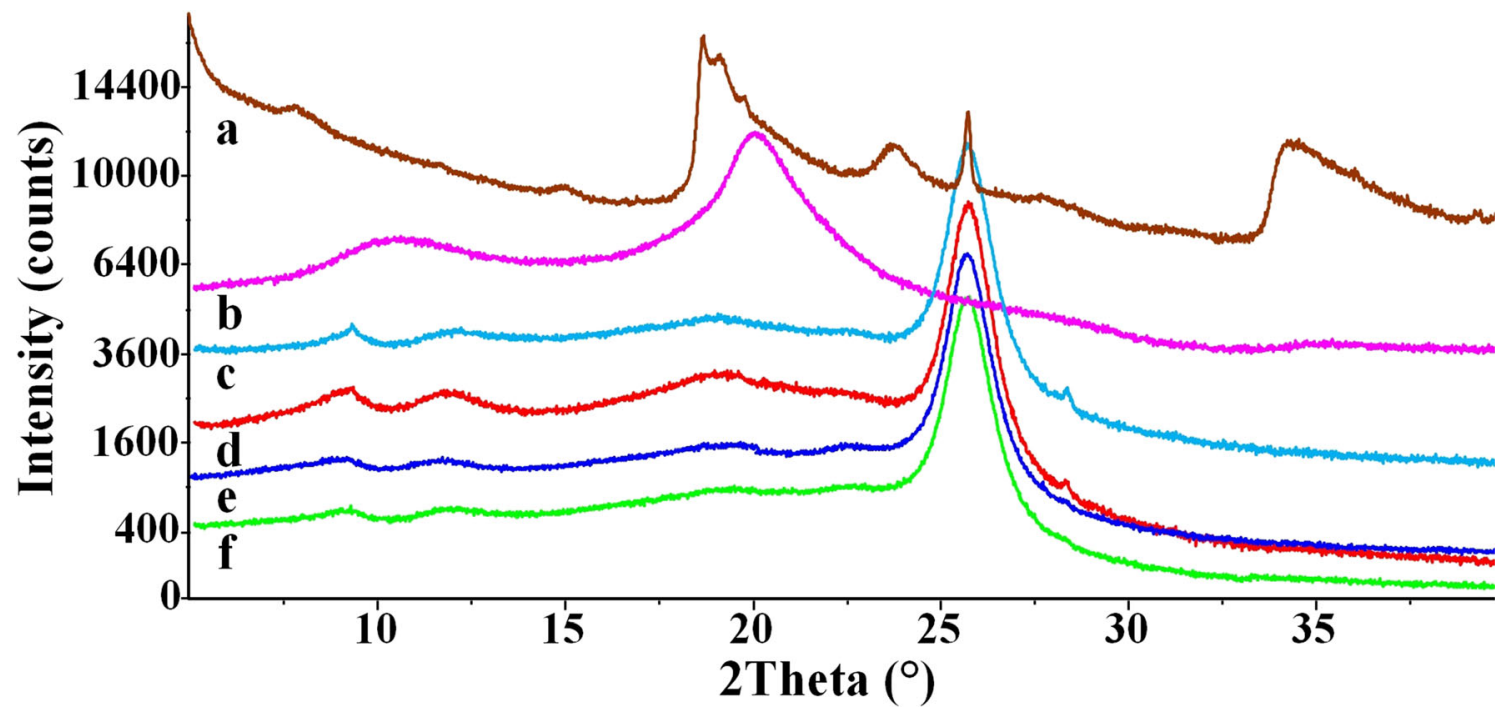

Fig. 3 XRD patterns of the ODA-MMT (a), pure chitosan (b), chitosan/ODA-MMT nanocomposites (c), and CM nanocomposite entrapment with different black cumin (BC) content $(1,2.5,5 \%, w / v)$ referred as CMBC-1 (d), CMBC-2.5 (e), and CMBC-5 (f), respectively

morphology with occasional flocculation. Therefore, on the results of XRD patterns and FTIR spectra, it is clearly indicated that the ODA-MMT was formed intercalated and exfoliated structures in CMBC film [26, 29].

Last, the surface morphology of the nanocomposites was studied by SEM. Good and random dispersion of ODA-MMT with various particle sizes in CS matrix was observed (Fig. 4). The dispersion of the ODA-MMT in the CS medium between clay and polymer matrix was observed from SEM images. The smoothness of the surfaces is decreased by increased $\mathrm{BC}$ content into the $\mathrm{CM}$ nanocomposite. This is because of the coagulation of the $\mathrm{BC}$ compounds in case of high contents. CS polymer and ODA-MMT interaction, which lead to polar groups of clay and polymer, was also observed [30]. At lower BC content (1 wt\%, Fig. 4a, b), the CMBC-1 shows the existence of intercalated structures. With increasing the content of
Fig. 4 SEM images of chitosan/ ODA-MMT/black cumin nanocomposites: CMBC-1 (a, b) CMBC-2.5 (c, d), and CMBC-5 $(\mathbf{e}, \mathbf{f})$
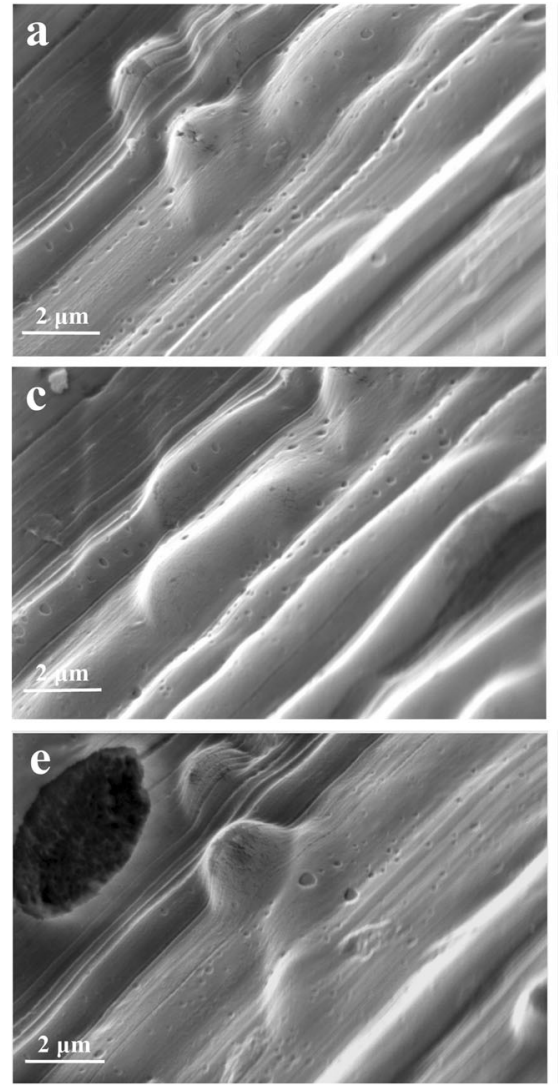
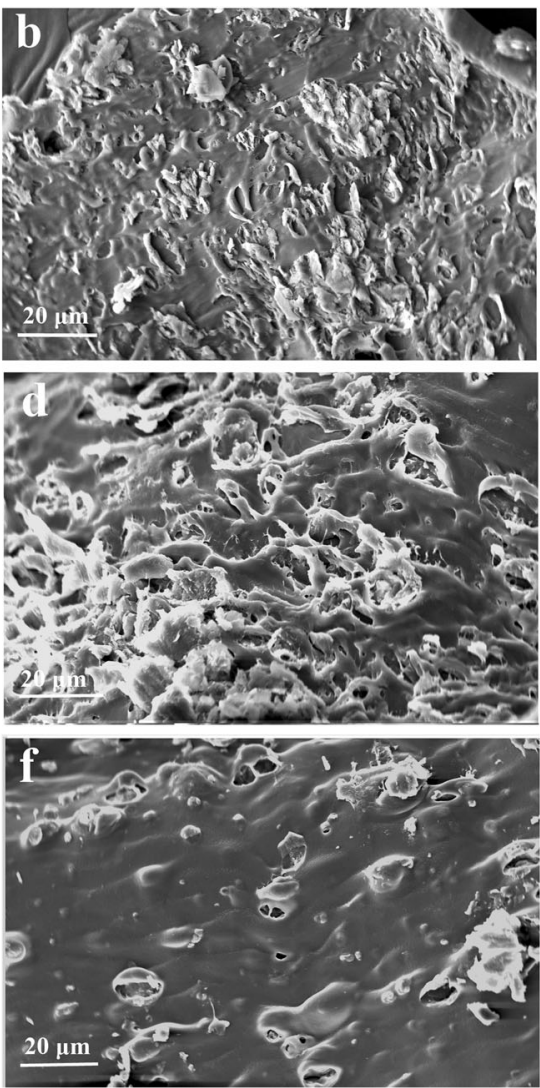
the BC (2.5 wt\% (Fig. 4c, d) and 5 wt\% (Fig. 4e, f)), the CMBC-2.5 and CMBC-5 clearly show intercalated and exfoliated morphology. The exfoliated ODA-MMT exhibited a structure composed of layers which flattening out in parallel to the surface, where each layer had an undefined shape with a size range of 10-20 $\mathrm{nm}$. The increased extent of intercalation is consistent with the results from XRD discussed earlier.

\subsection{Antimicrobial Activity}

We assessed whether the prepared CMBC nanocomposites can inhibit the growth of the common human and food pathogens. Pristine CS, ODA-MMT, black cumin extract, and all the chitosan nanocomposites (CMBC-1, CMBC-2.5, and CMBC-5) were screened, and the antimicrobial effect was evaluated by disc diffusion test (Fig. 5). The samples containing only black cumin, CS, and ODA-MMT did not show significant zone of growth inhibition, and the disc containing gentamicin exhibited significantly larger zone of inhibition compared to this samples $(\sim 28 \pm 1.2 \mathrm{~mm})$. All the three nanocomposites (CMBC-1, CMBC-2.5, and CMBC-5) exhibited significantly larger inhibition zones of growth (Fig. 5) compared to those of pure CS, ODA-MMT, or black cumin. Interestingly, the zone of inhibition for the tested nanocomposites increased with the increasing content of black cumin (i.e., 16.78, 19.26, and $21.49 \mathrm{~mm}$ for CMBC-1, CMBC-2.5, CMBC-5, respectively) against all tested microorganisms. To understand the "concentration" dependence for the antimicrobial activity of obtained nanocomposites, we evaluated that neither the ODA-MMT nor the CS matrix should be regarded as the conventional "antimicrobial agent," since they did not show significant antimicrobial activity according to our control tests.

The increased antimicrobial effect with increasing content of $\mathrm{BC}$ was determined by the disc diffusion assay. The antimicrobial activity studies of the CMBCs illustrated that the nanocomposites inhibited strongly the growth of the tested Gram-negative bacteria (E. coli and S. typhimurium) than Gram-positive bacteria (S. aureus and S. mutans) within increased content of black cumin from 1 to $5 \mathrm{w} \%$. According to this evaluation, the antimicrobial effect of the CMBC-5 nanocomposite against tested Gram-positive bacteria illustrated almost near value of inhibition zone compared to the effect of gentamicin (VI $\sim 92 \%$ ). For our materials without any additional antimicrobial agents, the strong antimicrobial activity is presumably related to the exfoliated ODA-MMT nanofillers dispersed in the CS matrix, which is corroborated by the observation that $\mathrm{CMBC}-5$ with the highest level of $\mathrm{BC}$ provided the strongest antimicrobial effect.

\section{Conclusions}

In this work, we have reported the preparation of a series of green inexpensive chitosan containing organic modified montmorillonite nanocomposites within black cumin extract.

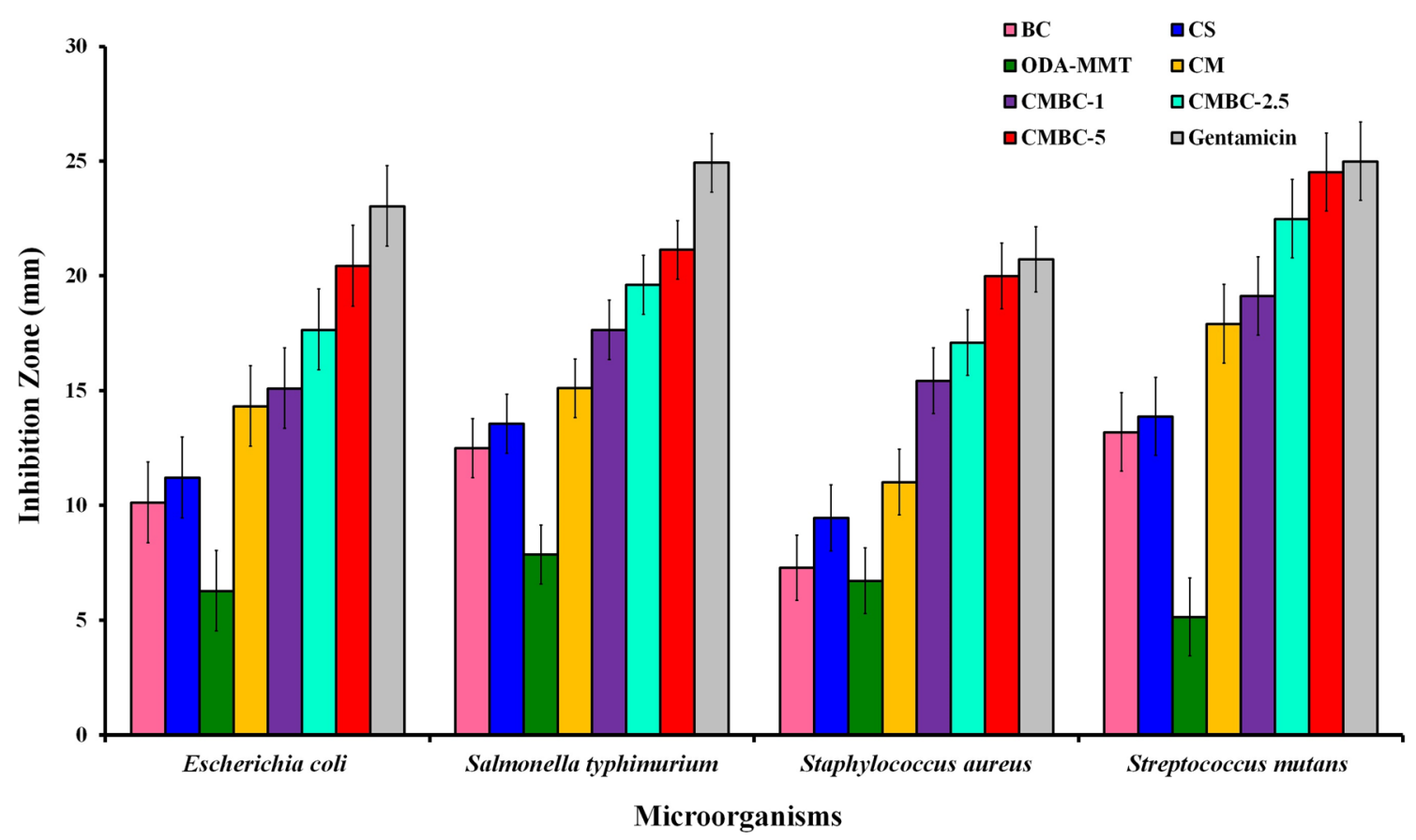

Fig. 5 Antimicrobial activity of black cumin extract (BC), pristine chitosan (CS), ODA-MMT, their films: CM, chitosan/ODA-MMT; CMBC-1, chitosan/ODA-MMT/black cumin with black cumin concentration $1 \%(w / v)$; CMBC-2.5, chitosan/ODA-MMT/black cumin with black cumin concentration $2.5 \%(w / v)$; CMBC-5, chitosan/ODA-MMT/ black cumin with black cumin concentration $5 \%(w / v)$, expressed as inhibition zones (mm) 
For the first time, significant inhibition against the humanand food-related bacteria was achieved by using the chitosan/ODA-MMT/BC nanocomposites. We believe that the exfoliated ODA-MMT nanofillers dispersed in the chitosan matrix and bioactive nature of $\mathrm{BC}$ is the key factor for the peculiar observation. It is expected that our new chitosanbased nanocomposites can be potentially used for application of those new green nanocomposites as packaging materials, medical textile, or various biomedical devices. Besides those applications, such sustainable nanocomposites may also have the potential in the development of new antibacterial drugs or additives.

\section{References}

1. Aranaz, I., Mengíbar, M., Harris, R., Paños, I., Miralles, B., Acosta, N., Galed, G., \& Heras, Á. (2009). Functional characterization of chitin and chitosan. Current Chemical Biology, 3, 203-230.

2. Wang, S. F., Hu, Y., Zong, R. W., Tang, Y., Cheng, Z. Y., \& Fan, W. C. (2004). Preparation and characterization of flame retardant ABS/ montmorillonite nanocomposite. Applied Clay Science, 25(1-2), 49-55.

3. Darder, M., Colilla, M., \& Ruiz-Hitzky, E. (2003). Biopolymer-clay nanocomposites based on chitosan intercalated in montmorillonite. Chemistry of Materials, 15, 3774-3780.

4. Wang, S., Lu, A., \& Zhang, L. (2016). Recent advances in regenerated cellulose materials. Progress in Polymer Science, 53, 169206.

5. Reddy, J. P., \& Rhim, J. W. (2014). Isolation and characterization of cellulose nanocrystals from garlic skin. Materials Letters, 129, 20 23.

6. Lv, F., Wang, C., Zhu, P., \& Zhang, C. (2015). Isolation and recovery of cellulose from waste nylon/cotton blended fabrics by 1-allyl3-methylimidazolium chloride. Carbohydrate Polymers, 123, 424431.

7. Haafiz, M. K. M., Hassan, A., Zakaria, Z., Inuwa, I. M., \& Islam, M. S. (2013). Physicochemical characterization of cellulose nanowhiskers extracted from oil palm biomass microcrystalline cellulose. Materials Letters, 113, 87-89.

8. Rao, M., Kanatt, S., Chawla, S., \& Sharma, A. (2010). Chitosan and guar gum composite films: Preparation, physical, mechanical and antimicrobial properties. Carbohydrate Polymers, 82, 1243-1247.

9. Bonilla, J., Fortunati, E., Atarés, L., Chiralt, A., \& Kenny, J. M. (2014). Physical, structural and antimicrobial properties of poly vinyl alcohol-chitosan biodegradable films. Food Hydrocolloids, $35,463-470$.

10. Ray, S. S., \& Okamoto, M. (2003). Polymer/layered silicate nanocomposites: A review from preparation to processing. Progress in Polymer Science, 28(11), 1539-1641.

11. Sun, J. X., Sun, X. F., Zhao, H., \& Sun, R. C. (2004). Isolation and characterization of cellulose from sugarcane bagasse. Polymer Degradation and Stability, 84, 331-339.

12. Jiang, F., \& Hsieh, Y. L. (2015). Cellulose nanocrystal isolation from tomato peels and assembled nanofibers. Carbohydrate Polymers, 122, 60-68.

13. Duran, M., Aday, M. S., Zorba, N. N. D., Temizkan, R., Büyükcan, M. B., \& Caner, C. (2016). Potential of antimicrobial active packaging 'containing natamycin, nisin, pomegranate and grape seed extract in chitosan coating'to extend shelf life of fresh strawberry. Food and Bioproducts Processing, 98, 354-363.

14. Poletto, M., Ornaghi, H. L., \& Zattera, A. J. (2014). Native cellulose: Structure, characterization and thermal properties. Materials, 7, 6105-6119.

15. Moradi, M., Tajik, H., Rohani, S. M. R., Oromiehie, A. R., Malekinejad, H., Aliakbarlu, J., \& Hadian, M. (2012). Characterization of antioxidant chitosan film incorporated with Zataria multiflora Boiss essential oil and grape seed extract. LWT- Food Science and Technology, 46, 477-484.

16. Davis, P. H. (1965). Flora of Turkey and the East Aegean Islands, 6. Edinburgh: University Press.

17. Davis, P. H. (1988). Flora of Turkey and the East Aegean Islands, 10. Edinburgh: University Press.

18. Landa, P., Marsik, P., Havlik, J., Kloucek, P., Vanek, T., \& Kokoska, L. (2009). Evaluation of antimicrobial and anti-inflammatory activities of seed extracts from six Nigella species. Journal of Medicinal Food, 12(2), 408-415.

19. Zohary, M. (1983). The genus Nigella (Ranunculaceae)-A taxonomic revision. Plant Systematics and Evolultion, 142, 71-107.

20. Atia, F., Mountian, I., Simaels, J., Waelkens, E., \& Van Driessche, W. (2002). Stimulatory effects on Na+ transport in renal epithelia induced by extracts of Nigella arvensis are caused by adenosine. Journal of Experimental Biology, 205, 3729-3737.

21. Kaya, M. S., Kara, M., \& Özbek, H. (2003). Çörek otu (Nigella sativa) tohumunun insan hücresel bağıșıklık sisteminin $\mathrm{CD} 3+$, CD4+, CD8+ hücreleri ve toplam lökosit sayısı üzerine etkileri. Genel Tip Dergisi, 13, 109-112.

22. Kökdil, G., \& Y1lmaz, H. (2005). Analysis of the fixed oils of the genus Nigella L.(Ranunculaceae) in Turkey. Biochemical Systematics and Ecology, 33, 1203-1209.

23. Abdel-Daim, M. M., \& Ghazy, E. W. (2015). Effects of Nigella sativa oil and ascorbic acid against oxytetracycline-induced hepato-renal toxicity in rabbits. Iranian Journal of Basic Medical Sciences, 8, 221-227.

24. Beheshti, F., Khazaei, M., \& Hosseini, M. (2016). Neuropharmacological effects of Nigella sativa. Avicenna Journal of Phytomedicine, 6, 124-141.

25. National Committee for Clinical Laboratory Standards Performance standards for antimicrobial disk susceptibility tests (NCCLS). (2003). Wayne, PA Approved standard, 8th edn. M2A8.

26. Liu, K. H., Liu, T. Y., Chen, S. Y., \& Liu, D. M. (2008). Drug release behavior of chitosan-montmorillonite nanocomposite hydrogels following electrostimulation. Acta Biomaterialia, 4, 1038-1045.

27. Peng, P., Yang, Z., Wu, M., Zhang, Q., \& Chen, G. (2013). Effect of montmorillonite modification and maleic anhydrate-grafted polypropylene on the microstructure and mechanical properties of polypropylene/montmorillonitenanocomposites. Journal of Applied Polymer Science, 130, 3952-3960.

28. Filho, G. R., de Assuncao, R. M. N., Vieira, J. G., Meireles, C. D. S., Cerqueira, D. A., Barud, H. D. S., Ribeiro, S. J. L., \& Messaddeq, Y. (2007). Characterization of methylcellulose produced from sugar cane bagasse cellulose: Crystallinity and thermal properties. Polymer Degradation and Stability, 92, 205-210.

29. Wang, S. F., Shen, L., Tong, Y. J., Chen, L., Phang, I. Y., Lim, P. Q., \& Liu, T. X. (2005). Biopolymer chitosan/montmorillonite nanocomposites: Preparation and characterization. Polymer Degradation and Stability, 90(1), 123-131.

30. Xu, D. F., Cai, J., \& Zhang, L. N. (2016). High strength cellulose composite films reinforced with clay for applications as antibacterial materials. Chinese Journal of Polymer Science, 34(10), 12811289. 